\title{
Influence of different CoCrMo counterfaces on wear in UHMWPE for artificial joints
}

\author{
Victor A. González-Mora, Michael Hoffmann, Rien Stroosnijder, Eduardo Espinar ${ }^{1}$, José Maria \\ Llamas $^{1}$, Mariano Fernández-Fairén ${ }^{2}$, Francisco Javier Gil ${ }^{2}$ \\ ${ }^{1}$ Department of Ortodoncia, Facultad de Odontologia, Universidad de Sevilla, Sevilla, Spain; \\ ${ }^{2}$ CREB, Department of Ciencia de Materiales e Ingeniería Metalúrgica, ETSEIB, Universidad Politécnica de Cataluña, Barcelona, \\ Spain. \\ Email: francesc.xavier.gil@upc.edu
}

Received 20 December 2010; revised 20 January 2011; accepted 1 March 2011.

\begin{abstract}
Wear tests were carried out to study the effect of various counterface materials in the wear behaviour of Ultra High Molecular Weight Polyethylene (UHMWPE). The materials used as counterfaces were based on varieties of CoCrMo: 1) forged (handpol-ished) CoCrMo; 2) forged (mass-finished) CoCrMo; 3) cast (mass-finished) CoCrMo. Additionally, two coatings were proposed: 1) a CoCrMo coating applied to the forged CoCrMo alloy by means of physical vapour deposition (PVD); 2 ) a $\mathrm{ZrO}_{2}$ coating applied to the forged CoCrMo alloy by means of plasma-assisted chemical vapour deposition (PACVD). The reciprocating pin-on-flat (RPOF) device for pin-on-disk wear testing was used for this study. The worn surfaces were observed using optical, atomic force and scanning electron microscopes.
\end{abstract}

Keywords: Wear; Artificial Joints; CoCrMo

\section{INTRODUCTION}

Decades of basic and clinical experimentation have resulted in a vast array of prosthetic designs and material combinations. However, there is still any consensus on which designs are the most appropriate and successful. All material combinations have certain drawbacks. According to Wang [1], "All prostheses will fail sometime. It is a race between the life of the patient and the life of the prosthesis" [1-3]. Therefore, the duty of researchers is continuing the search for finding better combinations of materials for artificial joints.

The material combinations used today include a polymer component for the acetabular cup in the hip joint, or a tibial plateau in the knee joint, and a metallic or ceramic counterface for the femoral head in the hip joint, or a metallic counterface for the femoral condyle in the knee joint. For the polymer component, ultra-high molecular weight polyethylene (UHMWPE) has been universally adopted. Nowadays, the most widely used components are couples (or sliding pairs) composed of UHMWPE and a metal counterface (generally a CoCr-based alloy). This material combination is called a "metal-on-polyethylene" artificial joint. In hip joints, a ceramic material (usually alumina or zirconia) can also be used as a counterface. This is called a "ceramic-onpolyethylene" joint. In recent years, there has been renewed interest in "metal-on-metal" and "ceramic-onceramic" artificial hip joints, in which both the femoral and acetabular components are made of metal or ceramic.

Many variables contribute to clinical success or failure in complex reconstructive procedures, such as a total joint replacement. These variables include patient selection, surgical techniques and prosthetic components. There are many reasons for failure during the life of a joint prosthesis. Early failures are often caused by infection, joint dislocation and/or the fracture of the replacement components. However, the main cause for most of the long-term failures is an aseptic loosening. With the advances in the design of the prosthesis and the fixation methods, wears of UHMWPE have replaced loosening as the main cause of failure in long-term implants $[1,2]$. It is generally recognized that microscopic polyethylene wear debris can induce adverse biological tissue reactions and subsequent bone resorption or osteolysis [1-5]. Wear particles of all types of biomaterials, especially UHMWPE, can apparently cause macrophages which may lead to an osteolytic reaction (either directly, or via mediator release) [3].

Concerns over UHMWPE wear have led to new designs and new material combinations for the articulating surfaces of artificial joints. Thus, metal and ceramic wear particles must also be considered. Osteolysis is 
related to particle accumulation. The size, concentration and, to a lesser extent, shape and chemical composition of the particles are the most important factors in bioenvironmental response to wear debris.

\section{MATERIALS AND METHODS}

The reciprocating pin-on-flat (RPOF) device is a special pin-on-disk (POD) wear tester that was designed in accordance with the ASTM F732-82 standard. This standard is the first specific standard in the field of biotribology. It sets the guidelines for a "laboratory method for evaluation of the friction and wear properties of combinations of materials that are being considered for use as the bearing surfaces of human total joint replacement prostheses" $[7,8]$. The standard is mainly intended for the evaluation of polymer material combinations.

The RPOF wear-test device is a tribosystem, in which an apparatus produces an oscillatory relative motion between the pins and plates. Normally, the pins are stationary while the plates have an oscillating motion. The motion is always in a horizontal plane and unidirectional (Figure 1). These "reciprocating" devices are so called because of the reciprocating oscillating movement of the plate with respect to the pin.

The tests on the RPOF wear-test method were performed as follows. The disks were mounted on a linear bearing while the pins were fixed and pressed against the disks. The motion of the RPOF machine is unidirectional and reciprocating, with a stroke length of $17 \mathrm{~mm}$. A load of $225 \mathrm{~N}$ (23 kg) was placed over the pins, resulting in a contact pressure of $3.5 \mathrm{MPa}$; this is the total standard knee replacement stress measured [4]. The pin contact area is considered to be $63.6 \mathrm{~mm}^{2}$. The frequency of the motion was $1 \mathrm{~Hz}$, or 1 cycle/second. Two stroke lengthsthose are one back-and-forth motion of the disks are considered one cycle. The wear on the UHMWPE pins was determined by weight loss measurements every 250,000 cycles, up to a total test length of one million cycles.

The test lubricant was replaced with fresh solution after every weighing stop. Distilled water was added during the test to compensate the water evaporation. A solution consisting of bovine serum and distilled water was used as test lubricant. The solution had a total protein concentration of $30 \mathrm{mg} / \mathrm{ml}$, which simulated the clinical situation [9]. The serum was purchased at Sigma-Aldrich (calf serum, bovine donor; product No. C9676). The adsorption of the protein constituents onto UHMWPE pins was determined using an additional control pin, which was loaded in the RPOF machine as the UHMWPE pins were loaded, but not applying any motion. The UHMWPE pins were cleaned and dried in accordance with the ASTM 1714 standard. A Mettler Toledo AT261 Delta Range ${ }^{\circledR}$ microbalance with an ac- curacy of $\pm 10 \mu \mathrm{g}$ was used to weigh the pins.

The pins were manufactured from a medical-grade GUR1120 UHMWPE bar, previously sterilised with standard $25 \mathrm{kGy}$ (2.5 Mrad) gamma radiation. The density of the UHMWPE was $0.9737 \mathrm{~g} / \mathrm{cm}^{3}$. The pins were $13 \mathrm{~mm}$ long and $9 \mathrm{~mm}$ in diameter. The disks were manufactured from five different counterface materials, all of which were CoCrMo alloys. Table 1 summarises the test conditions and materials.

The standard material in this study was a hot-forged

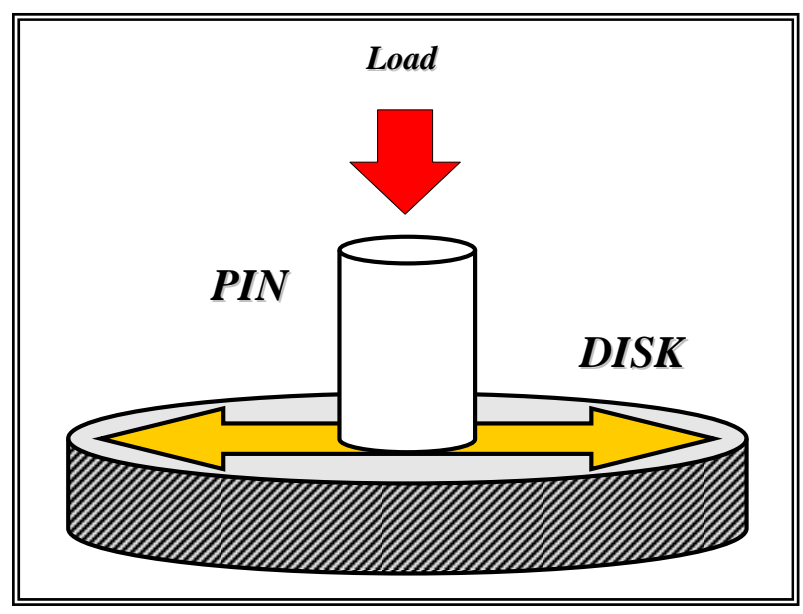

Figure 1. Motion/loading configuration of a RPOF wear-test machine showing the translating unidirectional movement of the pin on the plate. The yellow arrow shows the direction of sliding and the red arrow shows the direction of the load applied.

Table 1. Conditions of the RPOF wear tests.

\begin{tabular}{cc}
\hline Test parameter & Value \\
\hline Type of motion & Unidirectional (reciprocating) \\
Contact geometry & Flat-on-flat \\
Frequency & $1 \mathrm{~Hz}$ \\
Sliding distance/cycle & $17 \mathrm{~mm}$ \\
Contact area & $63.6 \mathrm{~mm}^{2}$ \\
Applied load & $23 \mathrm{~kg}$ (225 N) \\
Contact stress & 3.54 MPa \\
Test length & 1 million cycles (at intervals of 250,000) \\
Lubricant & 30 mg/ml initial protein content \\
Temperature & Room \\
UHMWPE component & GUR1120 \\
& Forged (hand-polished) CoCrMo \\
Forged (mass-finished) CoCrMo & Cast CoCrMo \\
Counterface component & Forged CoCrMo with a CoCrMo coating \\
& Forged CoCrMo with a ZrO2 coating \\
\hline
\end{tabular}


CoCrMo alloy. Table 2 shows the chemical composition of this material.

- Forged (hand-polished) CoCrMo

- Forged (mass-finished) CoCrMo

- Cast (mass-finished) CoCrMo

- In addition to the materials mentioned above, two coatings were employed. First, a CoCrMo coating applied to the forged CoCrMo alloy by means of physical vapour deposition (PVD). The coating had the same chemical composition as the substrate. The rationale for testing this kind of coating was related to the use of femoral components in Total Knee Replacements (TKRs).

The second coating was a $\mathrm{ZrO}_{2}$ coating applied to the forged CoCrMo alloy by means of plasma-assisted chemical vapour deposition (PACVD). The rationale for testing this kind of coating was the same as for the CoCrMo coating applied to forged CoCrMo.

For each counterface material, four disks were tested and at least three of them were considered for evaluation. A total of 40 wear tests were performed. Table 3 shows the roughness and hardness of each material.

\section{EXPERIMENTAL RESULTS AND DISCUSSION}

Figure 2 shows the wear results obtained with the RPOF tests for the UHMWPE specimens (pins). The volumetric wear $\left(\mathrm{mm}^{3}\right)$ of the UHMWPE pins is represented as a function of test duration (in cycles) and counterface type. The volumetric wear results are calculated according to the average of weight loss of three specimens for each material.

The standard deviations ranged from 0.01 to $0.05 \mathrm{mg}$, except for the CoCrMo coating. These measurement variations imply that the gravimetric wear determination is highly influenced by the intrinsic uncertainty of the measurement, with little weight losses in the UHMWPE.
Thus, for very early stages and especially for counterfaces producing very little weight loss in the UHMWPE specimen, the measurements have a high uncertainty. The CoCrMo coating had significantly higher standard deviations, ranging from 0.08 to $0.11 \mathrm{mg}$. The greater scatter for the CoCrMo coating is due to the higher sensitivity of the coating to scratches and third-body wear, which highly influence the surface roughness of the disks and thus weight loss in the UHMWPE.

The results shown in Figure 2 can be used to extrapolate the wear behaviour of UHMWPE to the next million cycles. However, it is more interesting to compare the wear rates of the sliding couples than to compare the volumetric wear after one million cycles of the wear test. Figure 3 shows data from Figure 2 for the first 250,000 cycles without standard deviations. This data is related to the initial stage of running-in wear and do not correspond to the stationary wear state. Wear-rate values are calculated from the slope of the linear regression fitting to the volumetric wear data. The $\mathrm{R}^{2}$ values of the linear fitting (greater than 0.92) indicate that the wear tests are highly reproducible and the wear rates are highly linear, except for the mass-finished alloys (both cast and forged), which had higher uncertainty due to low measurement accuracy for small weight losses. This is consistent with other studies $[10,11]$ and clinical observations [12,13], which have shown that the high initial wear rate is statistically higher by a significant amount than the wear rate thereafter.

The results show that the CoCrMo coating causes the highest UHMWPE wear of all the counterfaces tested. The CoCrMo coating wear rate is an order of magnitude higher than that caused by the mass-finished (forged) alloy, which caused the least UHMWPE wear in this study. The $\mathrm{ZrO}_{2}$ coating and the hand-polished (forged) CoCrMo alloy caused intermediate UHMWPE wear rates. The UHMWPE wear value for the $\mathrm{ZrO}_{2}$ coating is

Table 2. Chemical composition of the forged CoCrMo alloy (\%).

\begin{tabular}{ccccccccc}
\hline Component & $\mathrm{Cr}$ & $\mathrm{Mo}$ & $\mathrm{Mn}$ & $\mathrm{Ni}$ & $\mathrm{Si}$ & $\mathrm{Fe}$ & $\mathrm{C}$ & $\mathrm{N}$ \\
\hline Balance & $26-30$ & $5-7$ & $\max 1$ & $\max 1$ & $\max 1$ & $\max 0.7$ & $\max 0.35$ & $\max 0.25$ \\
\hline
\end{tabular}

Table 3. Roughness and hardness of each material tested.

\begin{tabular}{ccc}
\hline Material & Roughness Ra $(\mu \mathrm{m})$ & Hardness $(\mathrm{HVN})$ \\
\hline Hand-polished & $0.03 \pm 0.01$ & $673 \pm 21$ \\
Mass-finished & $0.05 \pm 0.01$ & $840 \pm 62$ \\
Cast CoCrMo & $0.05 \pm 0.01$ & $783 \pm 52$ \\
CoCrMo coating & $0.10 \pm 0.01$ & $884 \pm 28$ \\
$\mathrm{ZrO}_{2}$ coating & $0.06 \pm 0.01$ & $575 \pm 43$ \\
\hline
\end{tabular}




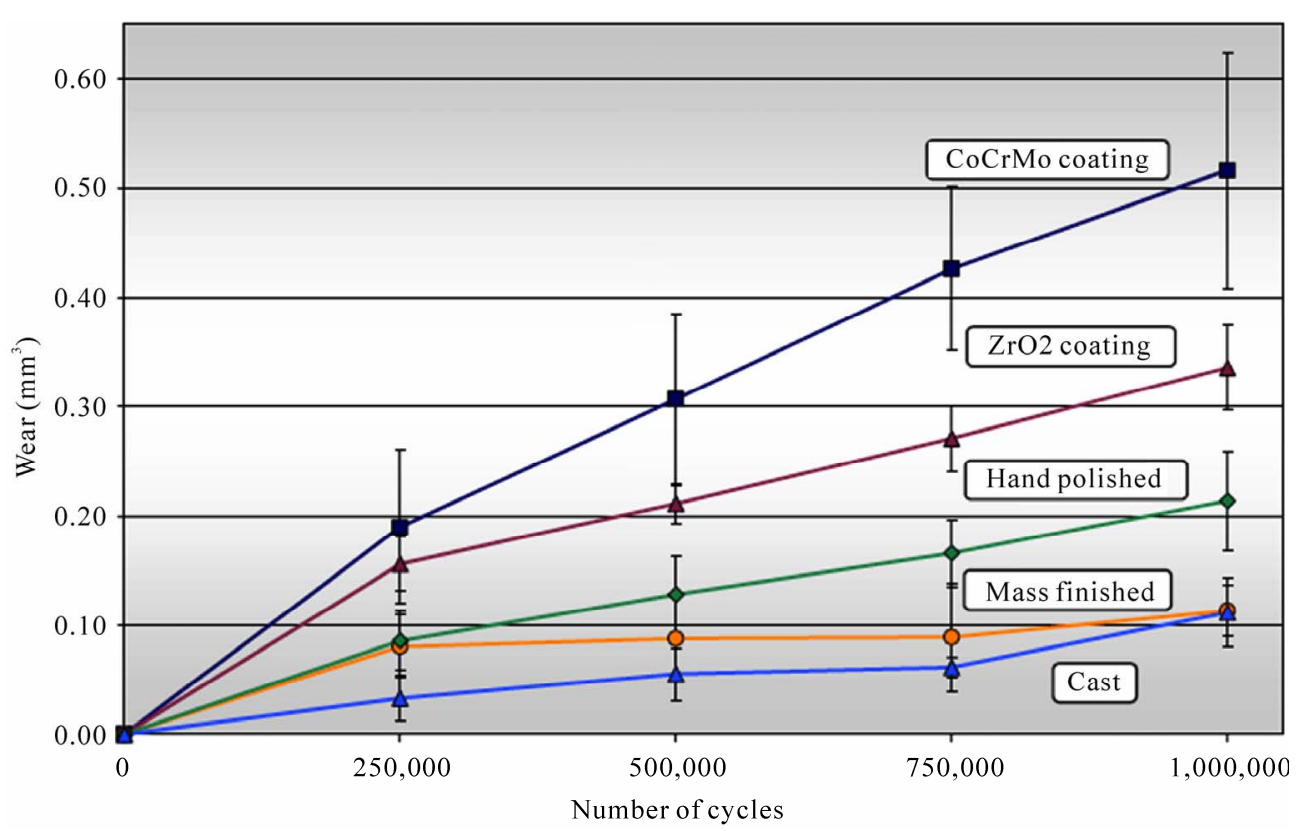

Figure 2. Average volumetric wear of UHMWPE pins sliding against various counterfaces.

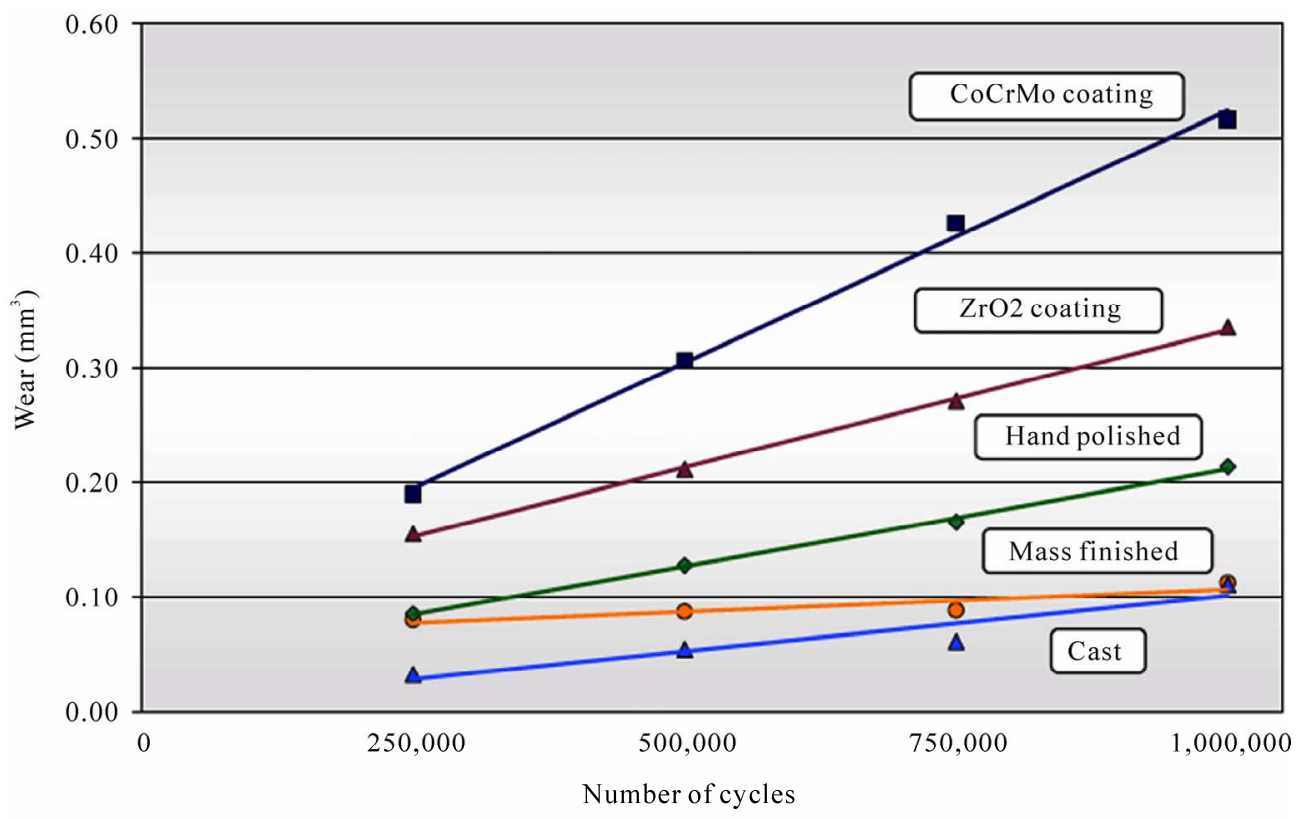

Figure 3. Wear rates of UHMWPE pins sliding against various counterfaces.

about half the wear value for the CoCrMo coating.

Different surface treatments (mass-finishing and handpolishing) on the forged CoCrMo alloys lead to signifycant differences in UHMWPE wear. The above data shows that the mass-finishing treatment on CoCrMo alloys causes less UHMWPE wear.

After the wear tests, the disk surface was observed with an optical microscope. All disks showed a certain degree of scratching. On the hand-polished alloys, the scratches were always parallel to the sliding direction
(Figure 4(a)) and were deeper and wider than those found on the mass-finished materials (Figure 4(b) and 4(c)). The scratches were most numerous on the CoCrMo coating surface (Figure 4(d)) and on the handpolished alloys. However, the scratches on the massfinished (forged and cast) alloys were shallow and hard to see, which may be due to the fact that the mass-finishing treatment on the surface of the CoCrMo alloys produces some hardening on the surface, rendering it more scratch-resistant than the hand-polished surface 


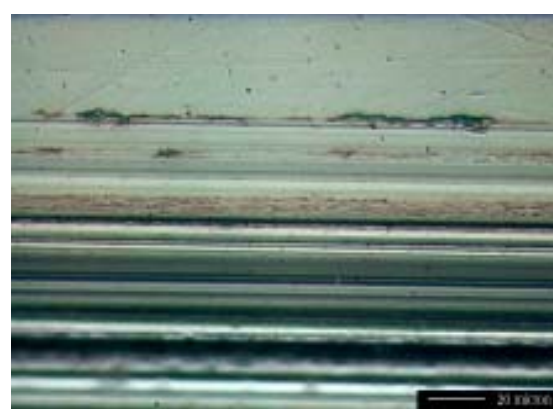

(a)

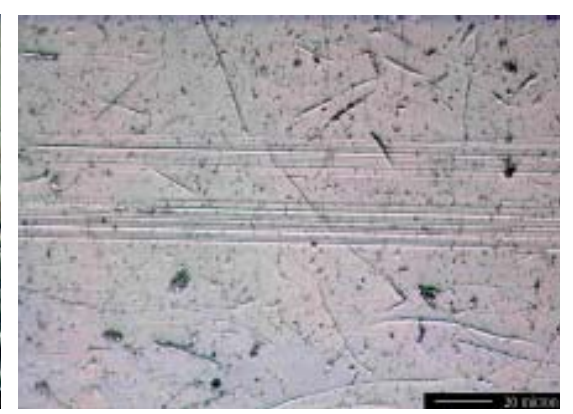

(b)

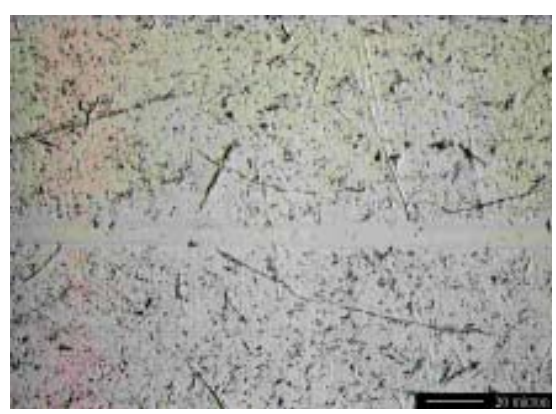

(c)

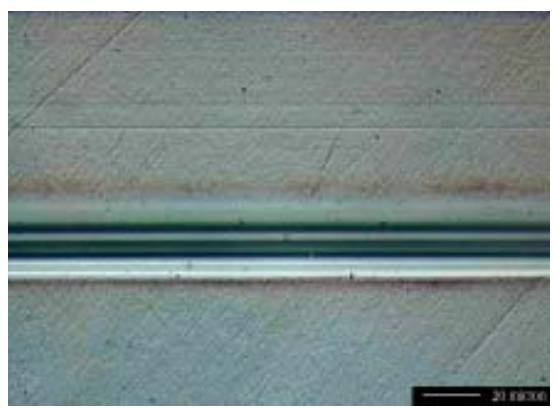

(d)

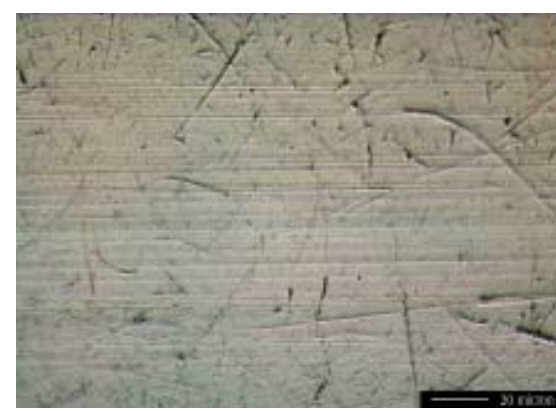

(e)

Figure 4. Optical micrographs showing the surface after the RPOF wear test. (a) hand-polished; (b) mass-finished; (c) cast; (d) CoCrMo coating; (e) $\mathrm{ZrO}_{2}$ coating.

\section{[14-17].}

For the CrCoMo coating samples, the worn UHMWPE surface presents numerous scars caused by the scratches of the disk counterfaces. The appearance of greater damage to the UHMWPE must be due to a rougher disk counterface. Therefore, greater UHMWPE wear is related to the roughening of the surface, which causes abrasive wear on the UHMWPE surface. For the other pin surfaces, the wear damage appears to be due to adhesion and creep; thus, the surfaces are smooth. As a result, the UHMWPE surface is flattened and has fewer scars. The differences in the wear surface of metal counterface are shown in Figure 5. The images were obtained using an atomic force microscope (AFM). This is consistent with in vivo observations, which showed that joint replacements which did not fail, or which had very little linear wear, maintained their initial low surface roughness counterface and had few scratches [17-21].

For the $\mathrm{ZrO}_{2}$ coating, we identified some surface defects in the coating itself (Figure 6(a)), which occurred during coating deposition. Those defects, together with the irregular mass-finished substrate surface and the well-known brittleness of $\mathrm{ZrO}_{2}$ coatings, may be the cause of the coating's fracture and subsequent detachment, which is shown in Figure 6(b). This kind of coating failure is responsible for the high degree of UHMWPE wear observed in the RPOF tests.
The hardness rankings are consistent with the wear results and surface observations for the bulk counterfaces. Thus, the mass-finished (forged) alloy causes less UHMWPE wear than the mass-finished (cast) alloy, and the second one causes less UHMWPE wear than the hand-polished (forged) alloy. Similarly, the mass-finished (forged) CoCrMo alloy is harder than the massfinished (cast) alloy, and the second one is harder than the hand-polished (forged) alloy. Therefore, the harder a surface is, the less UHMWPE wear it causes. The effect of counterface hardness on UHMWPE wear is due to the fact that hard surfaces are more resistant to scratching and, therefore, produce less UHMWPE wear, since an increase in surface roughness leads to an exponential increase in UHMWPE wear [22-24].

The UHMWPE wear caused by the $\mathrm{ZrO}_{2}$ coating is consistent with the assumption that softer counterfaces cause more UHMWPE wear. Additionally, AFM and SEM observations of the worn surfaces showed that the coating itself is highly resistant but tends to delaminate due to deposition defects [25].

The CoCrMo coating has the highest hardness value. This should make it extremely resistant to scratching (or, at the very least, more so than the bulk materials examined). Under the prevailing experimental conditions, however, the CoCrMo coating produced the highest UHMWPE wear in this study. Additionally, the AFM 


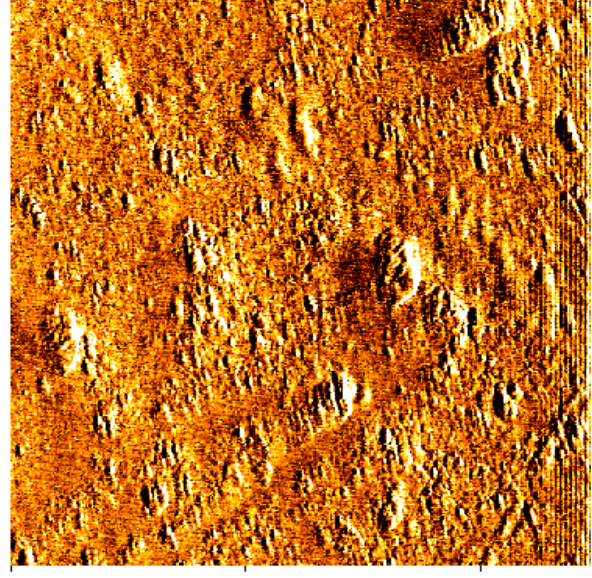

2

(a)

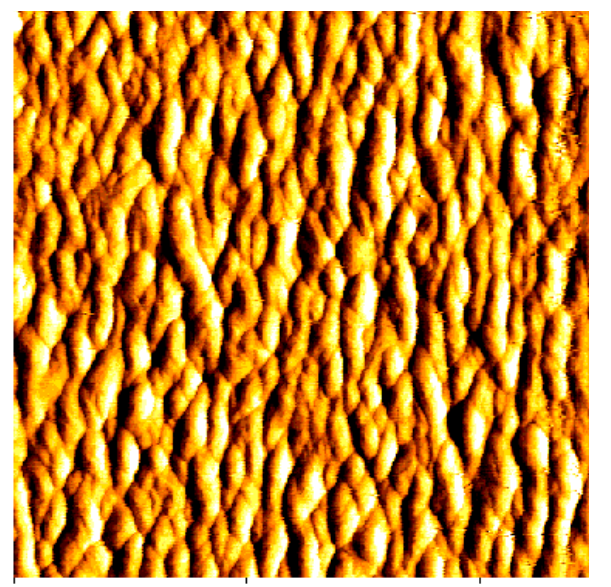

$\longleftrightarrow 1 \mu \mathrm{m} \quad$ Before

(a)

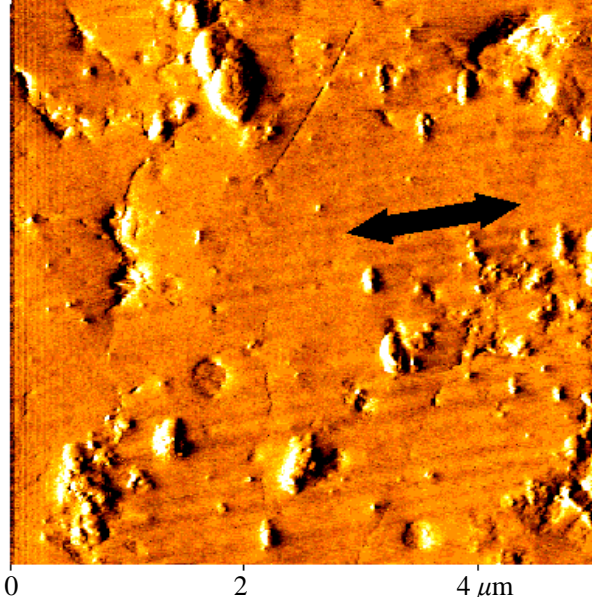

(b)

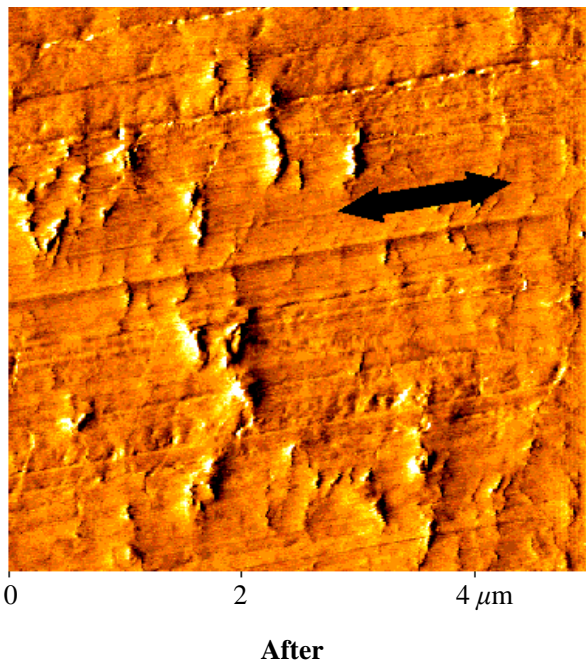

(b)

Figure 5. AFM images of the hand-polished (forged) CoCrMo alloy and of the CoCrMo coating, before and after the wear test. The black arrows show the direction of sliding.

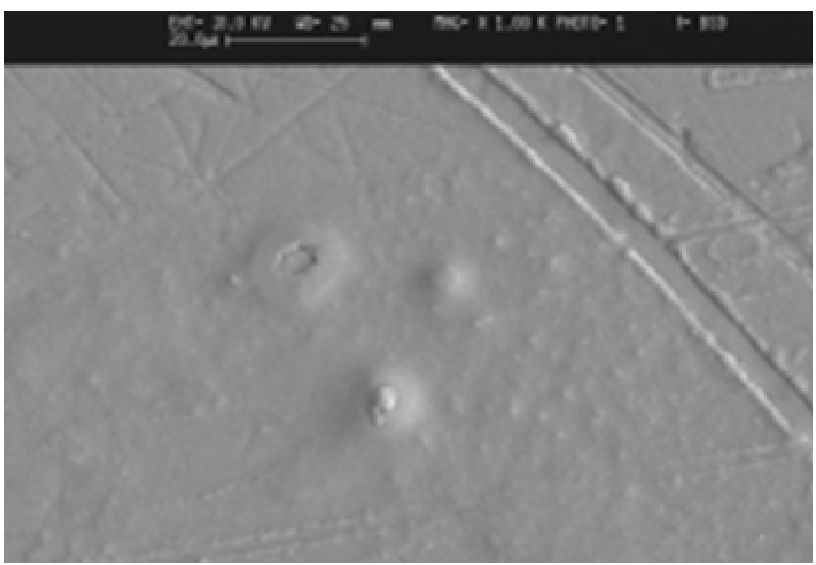

(a)

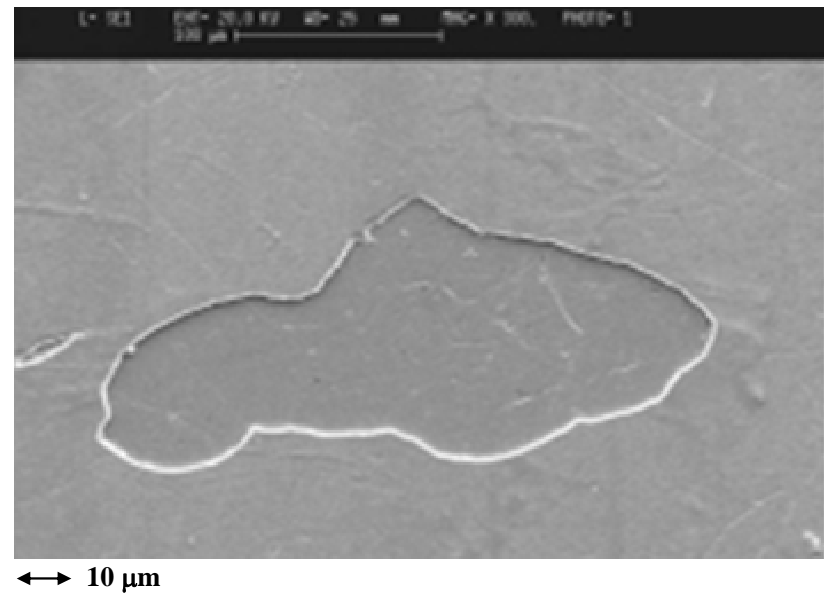

(b)

Figure 6. SEM micrographs of the $\mathrm{ZrO}_{2}$ coating surface. (a) as-received surface showing coating deposition defects; (b) surface after the wear test showing the failure of the coating by fracture and detachment. 
observation of the worn CoCrMo-coated surface showed a large number of scratches and therefore greater surface roughness, which causes high UHMWPE wear. Furthermore, coating fragments may favour third-body wear mechanisms, which also roughen the coating's surface.

\section{CONCLUSIONS}

The results obtained with the RPOF wear tests have demonstrated that the CoCrMo coating caused the highest UHMWPE wear of all the counterfaces tested. The $\mathrm{ZrO}_{2}$ coating and the hand polished (forged) CoCrMo alloy produced intermediate UHMWPE wear rates and the mass finished (forged and cast) alloys produced the lowest UHMWPE wear. The effect of the counterface hardness in the UHMWPE wear is due to the fact that hard surfaces are more resistant against scratching and consequently produces less UHMWPE wear, since an increase in the surface roughening produces an exponential increase in the UHMWPE wear.

\section{REFERENCES}

[1] Wang, A., Stark, C. and Dumbleton, J.H. (1996) Mechanistic and morphological origins of ultra-high molecular weight polyethylene wear debris in total joint replacement prostheses. Proceedings of the Institution of Mechanical Engineers, Part H: Journal if Engineering in Medicine, 210, 141-156. doi:10.1243/PIME_PROC_1996_210_407_02

[2] Murray, D. and Rushton, $\bar{N}$. (1990) Macrophages stimulate bone resorption when they phagocytose particles. Journal of Bone and Joint Surgery, 72B, 988-992.

[3] Howie, D. and McGee, M. (1996) Wear and osteolysis in relation to prostheses design and materials. Medical Applications of Titanium and its Alloys, ASTM STP 1272, 234-239.

[4] Essner, A., Schmidig, G. and Wang, A. (2005) The clinical relevance of hip joint simulator testing: In vitro and in vivo comparisons. Wear, 259, 882-886. doi:10.1016/j.wear.2005.02.105

[5] McGee, M., Howie, D., Neale, S., Haynes, D. and Pearcy, M. (1997) The role of polyethylene wear in joint replacement failure. Proceedings of the Institution of Mechanical Engineers, Part H: Journal of Engineering in Medicine, 211, 65-72. doi:10.1243/0954411971534692

[6] Green, T., Fisher, J., Stone, M., Wroblewski, B. and Ingham, E. (1998) Polyethylene particles of a 'critical size' are necessary for the induction of cytokines by macrophages in vitro. Biomaterials, 19, 2297-2302. doi:10.1016/S0142-9612(98)00140-9

[7] Sajewicz, E. (2006) On evaluation of wear resistance of tooth enamel and dental materials. Wear, 260, 1256-1261. doi:10.1016/j.wear.2005.08.010

[8] Saikko, V.A. (1998) Multidirectional motion pin-on-disk wear test method for prosthetic joint materials. Journal of Biomedical Materials Research, 41, 58-64. doi:10.1002/(SICI)1097-4636(199807)41:1<58::AID-JB M7>3.0.CO;2-P

[9] Wallbridge, N. and Dowson, D. (1998) The walking activity of patients with artificial hip joints. Engineering in
Medicine, 11, 95-96.

doi:10.1243/EMED_JOUR_1982_011_023_02

[10] Wang, A., Polineni, V., Essner, A., Stark, C. and Dumbleton, J. (1998) The impact of lubricant protein concentration on the outcome of hip joint simulator wear testing. 24th Annual Meeting of the Society for Biomaterials, San Diego, 22-26 April 1998.

[11] Gil, F.J. and Planell, J.A. (1999) Effect of copper addition on the superelastic behavior of $\mathrm{Ni}$-Ti shape memory alloys for orthodontic applications. Journal of Biomedical Materials Research, 48, 682-688. doi:10.1002/(SICI)1097-4636(1999)48:5<682::AID-JBM 12>3.0.CO;2-M

[12] Saikko, V. (1992) Wear and friction properties of prosthetic joint materials evaluated on a reciprocating pin-on-flat apparatus. Wear, 166, 169-178. doi:10.1016/0043-1648(93)90259-O

[13] Bamelet, V., Fridici, V., Abry, J.C. and Kapsa, P.H. (2007) Wear, 1, 1066-1071.

[14] Gil, F.J., Manero, J.M. and Planell, J.A. (1995) Effect of grain size on the martensitic transformation in NiTi alloy. Journal of Materials Science, 30, 2526-2530. doi:10.1007/BF00362129

[15] Streicher, M. (1995) Tribology of artificial joints. Springer Verlag, Berlin.

[16] Schmidt, M., Weber, H. and Schön, R. (1996) Cobalt chromium molybdenum metal combination for modular hip prostheses. Clinical Orthopaedics and Related Research, 329s, 35-47. doi:10.1097/00003086-199608001-00004

[17] Saikko, V. (1995) A three-axis hip joint simulator for wear and friction studies on total hip prostheses. The Journal of Engineering in Medicine, 210, 173-185.

[18] Gil, F.J. and Planell, J.A. (1998) Shape memory alloys for medical applications. Journal of Engineering in Medicine, Institution Mechanical Engineers, 212, 473-488.

[19] Wall, C.M., Eberle, D.C., Treuhaft, M.B. and Arps, J.H. (2005) Technique for high-sensitivity "in vitro" wear measurement of UHMWPE hip joint liners using radioactive tracer technology. Wear, 259, 964-971. doi:10.1016/j.wear.2005.02.039

[20] Dowson, D., Taheri, S. and Wallbridge, N. (1987) The role of counterface imperfections in the wear of polyethylene. Wear, 119, 277-293. doi:10.1016/0043-1648(87)90036-6

[21] Peña, J., Solano, E., Mendoza, A., Casals, J., Planell, J.A. and Gil, F.J. (2005) Effect of the Ms transformation temperature on the wear behaviour of NiTi shape memory alloys for articular prosthesis. Bio-Medical Materials and Engineering, 15, 289-293.

[22] Manero, J.M., Gil, F.J., Ginebra, M.P., Planell, J.A., Artola, A., Goñi, I. and Gurruchaga, M. (2004) Wear Behaviour of the Pair Ti-6Al-4V-UHMWPE of Acrylic Bone Cements Containing Different Radiopaque Agent. Journal of Biomaterials Applications, 18, 305-311. doi:10.1177/0885328204041531

[23] Hall, R., Unsworth, A., Siney, P. and Wroblewski, B. (1996) Wear in retrieved Charnley acetabular sockets. Proceedings of the Institution of Mechanical Engineers, 210, 197-207. doi:10.1243/PIME_PROC_1996_210_413_02 
[24] Gil, F.J., Canedo, R., Padrós, A., Bañeres, M.V. and Arano, J.M. (2003) Fretting corrosion behaviour of ball-and-socket joint on dental implants with different prosthodontic alloys. Bio-Medical Materials Engineering, 13, 27-34.

[25] Wang, A., Polineni, V., Stark, C. and Dumbleton, J. (1998)
The impact of lubricant protein concentration on the outcome of hip joint simulator testing. 44th Annual Meeting, Orthopaedic Research Society, New Orleans, 16-19 March 1998, 1034-1039. 